\title{
Editorial
}

\section{Singapore Advances Intelligent Nation Masterplan}

The vibrant direction of Singapore's future is clearly focused on its Masterplan: An Intelligent Nation, A Global City, Powered by Infocomm. This city-state of some 5 million has not only set ambitious goals to accomplish by 2015 , it already has many important achievements to record.

The Singapore 2015 Strategy incorporates the full range of essential components essential for transforming the country. These are (1) to establish an ultrahigh speed, pervasive, intelligent and trusted infocomm infrastructure; (2) to develop a globally competitive infocomm industry, (3) to develop an infocommsavvy workforce and globally competitive infocomm manpower, and (4) to spearhead the transformation of key economic sectors, government and society through more sophisticated and innovative use of infocomm.
The Infocomm Development Authority (IDA) of Singapore has been directing many of the transformative initiatives to and designed an integrated approach to developing infocomm in the country. Although the objectives and approaches of the Singapore plan are not unique among developed countries, the parallel pursuit of programs to create a competitive telecom market, strong involvement by business in infocomm enterprises in expanded trade, and extensive programs involving the society, may be the most ambitious of any nation.

It is no surprise, therefore, that Singapore consistently ranks very high on the e-Government ranking scales of the United Nations, Waseda University, World Economic Forum and other organizations.

Russell Pipe Editor in Chief 